\title{
Review of Research Techniques to Improve System Performance of Smart Antenna
}

\author{
T. G. Shivapanchakshari' ${ }^{1}$ H. S. Aravinda ${ }^{2}$ \\ ${ }^{1}$ Research Scholar, Dept. of Electronics and Communication Engineering, Cambridge Institute of Technology, Bangalore, India; \\ Visvesvaraya Technological University, Belagavi, India \\ ${ }^{2}$ Dept. of Electronics and Communication Engineering, Jagadguru Sri Shivarathreeshwara Academy of Technical Education, Ban- \\ galore, India \\ Email: tgsresearch2013@gmail.com
}

How to cite this paper: Shivapanchakshari, T.G. and Aravinda, H.S. (2017) Review of Research Techniques to Improve System Performance of Smart Antenna. Open Journal of Antennas and Propagation, 5, 83-98. https://doi.org/10.4236/ojapr.2017.52007

Received: April 15, 2017

Accepted: June 25, 2017

Published: June 28, 2017

Copyright ( $\odot 2017$ by authors and Scientific Research Publishing Inc. This work is licensed under the Creative Commons Attribution International License (CC BY 4.0).

http://creativecommons.org/licenses/by/4.0/

\begin{abstract}
Today, the significance of the wireless communication is known all over the world. In order to achieve the better communication, many techniques and methods have been introduced. Among these techniques, smart/adaptive antennas are trending topic in the research domain. The smart antennas consist of various antennas arrays and have the ability to optimize the radiation and reception of the desired signals dynamically. Also, in order to avoid or mitigate the interferences, smart antennas can introduce nulls in the interferers direction by adaptive updating of the weights linked at every antenna element. The smart antennas can also enhance the quality of reception and reduce the dropped calls. This paper discusses the various survey topics related to smart antennas, Adaptive Beam Forming $(\mathrm{ABF})$ algorithm etc. Also the various existing researches are discussed to know the research gap for future research scope.
\end{abstract}

\section{Keywords}

Smart Antenna, Switched Antenna, Adaptive Antenna, Beam-Forming Mechanism, Single/Multi Direction

\section{Introduction}

The wireless communication in today's generation plays an important role for communication. The growth in the use of wireless communication has led the demand of communication channels which can give improved spectrum utilization [1]. Thus, the smart antenna technology is widely used to improve the system capacity and performance. The signal processing in the smart antenna is meant to estimate the direction of arrival i.e. DOA and formation Adaptive Beam Forming (ABF) algorithm [2] [3]. The DOA of smart antenna estimates 
the direction of the interferer signals against the desired user. This estimation helps to adjust the weights of $\mathrm{ABF}$ by which radiated power get maximized towards the respective users and also the radiation nulls can be introduced in the interference signals directions [4]. The ABF can enhance the significant signals and also suppresses the interferences by performing the spatial filtering over the array element. Later, the every array elements weight factor can be changed according to the change in the signal environment. At normal condition, the ABF technique will effectively suppresses the interferences without change in the desired signal [1] [2]. In case of mobile communication, users always demand the high speed data sharing and voice services. Also, the operator also supports higher number of users in each base station in order to downgrade the network cost and make the affordable services for the users/subscribers [1] [2] [3]. Thus it needs to have higher capabilities/data rate in the wireless system. The drawback with the existing broadcast spectrum is limited; the traffic is increasing exponential in the limited/fixed bandwidth that will degrade the system performance and signal quality. In case, uni-directional antennas are utilized at base stations, then the reception and transmission of every user's signals will generate interference for other users present in the same system and by which the entire system becomes interference limited [1] [2] [3] [4] [5].

The existing wireless modems implements DSP in the time dimension via modulation, equalization and advanced coding techniques. The advantage of the SAs is to integrate and also exploit the multiple antennas generated extra dimensions at the transceivers to increase the overall performance of the network. The smart antenna based systems use the modem that will combine the multi-element antennas signals both in time and space [4]. The smart antenna can be used for both receiving and transmission at base stations and the user ends. The implementation of smart antenna at base station is more significant as the practical requirements/constraints limits the use of multiple antennas at user end. The smart antenna is the combination of several radiation antenna elements area and the DSP in order to receive and transmit in adaptive manner [2] [5] and [6]. The term adaptively is used because it automatically adjusts the dynamic directionalities of the radiation pattern in response to the signal environments. The smart antennas are also commonly known as the adaptive antennas, by which the smart antenna can enhance the channel capacity, extends the coverage range [2]. A smart antenna is an array of radiating antenna (ARA) elements combined with DSP to transmit and receive in the adaptive manner [3]. Means, it adjusts the directionality of its radiation pattern automatically in response to the signal environment. i.e. adaptive array antennas. Thus smart antenna can enhance channel capacity, coverage range extension etc. [4] [5] [6] [7].

In this paper a subjectively and extended survey of existing researches are discussed. The paper discusses about the existing techniques to improve system performance of smart antenna. The sectional portioning of the paper is given as. Section 2 discussed the concepts relating to the smart antennas, Section 3 gives the essentials of coverage and connectivity in smart antenna, section 4 describes 
the existing research survey, Section 5 describes research gap/research issues, Section 6 gives the future line of research, and Section 7 concludes the paper.

\section{Background}

This section gives the conceptual description of the Smart Antenna (SA), types, and techniques. The detailed explanation is described below.

\subsection{Smart Antenna}

Basically, a system with smart antennas exhibit number of antennas and also includes Digital Control (DC) system. The combination of the above gives the beam forming intelligence, thus the term smart antenna is originated. The addition of more number of elements in a smart antenna based system can bring changes in its physical system. Thus, because of composite system, antenna can perform shifting of signals before it gets transmitted to every successive element. The block diagram of smart antenna is shown in Figure 1, which consists of number of radiating elements, control unit, dividing/combining network. Based on the number of inputs the processor will control the feeder components of antenna and that optimizes the communication links. Thus, smart antennas are not just an antennas but acts as complete transceiver.

The smart antenna consists of set antenna components, which dynamically make changes in the antenna pattern to filter the interference, noise in the channel and solve the effect of the multipath fading over the interested signal. The smart antenna can receive and transfer the signals in both the spatially sensitive, adaptive manner. The smart antenna is effective due to combination of digital signal processing (DSP) software and antenna components. This combination enhances the performance/capacity in the wireless system. The smart an-

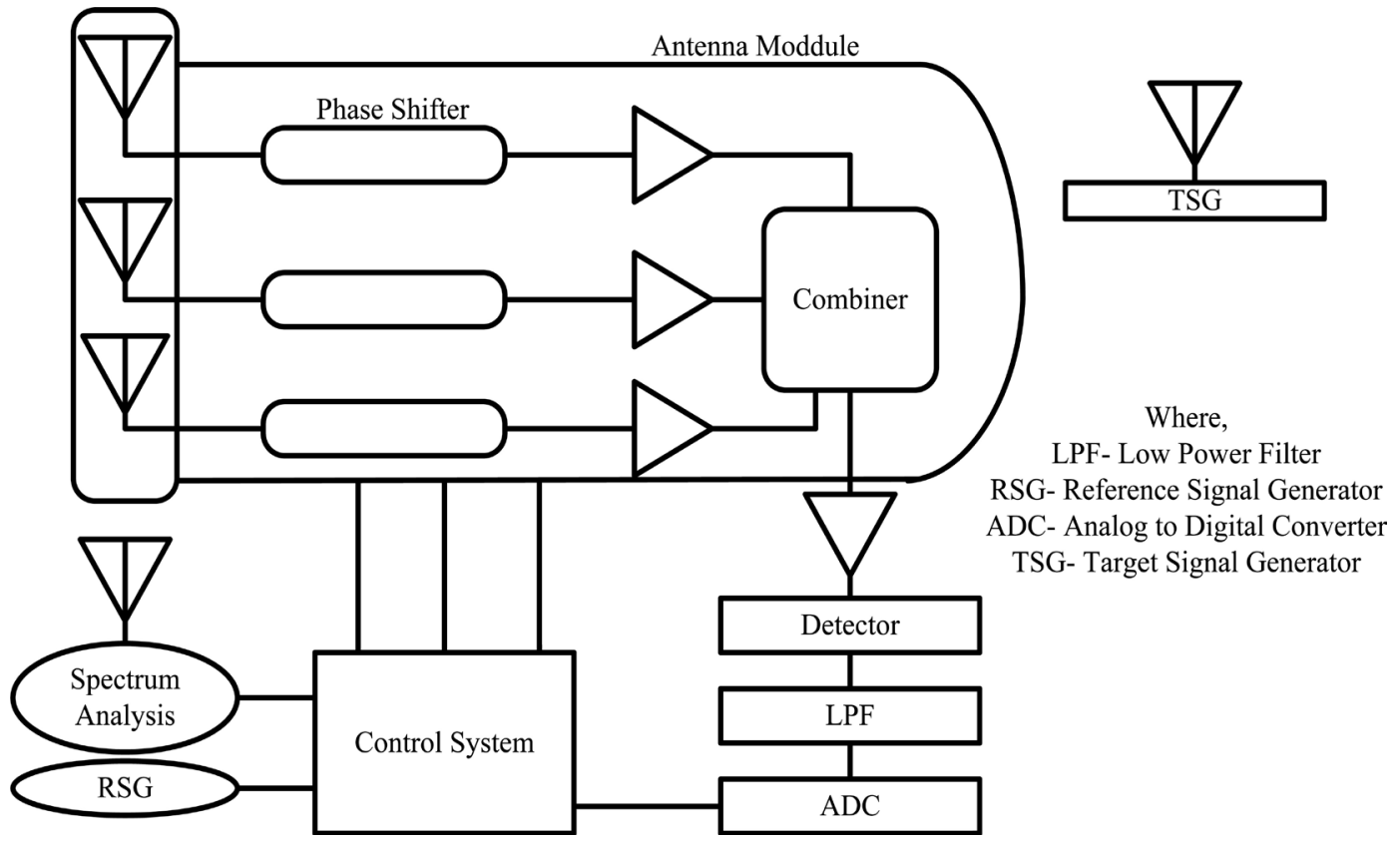

Figure 1. Architecture of Smart Antenna. 
tenna mainly located at the base stations due to need of sophisticated DSP.

\subsection{Types of Smart Antenna}

Due to the system complexity and higher power consumption, the smart antenna mechanisms are mainly considered at base station. Currently the smart antennas are used in various communication areas. From the conventional theory, smart antenna is basically classified as Switched Beam and Adaptive Array system (Figure 2). The switched beam system is further classified into single beam directional antenna and multi-beam directional antenna. Similarly, adaptive array system is further classified into single user beam forming and multi-user beam forming. Basically, switched beam system uses only fundamental forms of switching between apriori array beams and discrete directional antenna. On the other hand, adaptive beam forming is used for assessing amount of signals being received by the user.

\section{i) Adaptive Antennas (AAs)}

These are the antenna arrays which dynamically changes the antenna pattern to control the interference, multipath and noise. The main functionality of these antennas is that it sets enhances the received signals and also generate the beams to transmit the signals. These antennas release the broadcast energy to the narrow beam which cannot found in conventional antennas. Based on the signal distribution in air, this antenna optimizes the real time based distribution to the desired user and avoids the other users to occupy the same channel in same/adjacent/distant cell [1]-[8].

The significance of AAs is that the generated antenna beams can adaptively tracks the signal direction, i.e. no other signals are included in the interferer direction. In AAs, there is no inter-cell issue is found due to continuous tracking of user. The AAs can enhance the capacity in greater extent than switched beam. The AAs can have extensive signal processing through DSP. The main drawback of these antennas is that the cost of installation is very high [8].

\section{ii) Switched Beam (SB) systems}

These kind of systems are formed by a switch function among the distinct pre-defined beams/directive antennas of an array. The point at which the top level performance can be achieved as receiver power is considered in SB systems. These antennas exhibit high directivity, which helps to achieve some gain [8] [9].

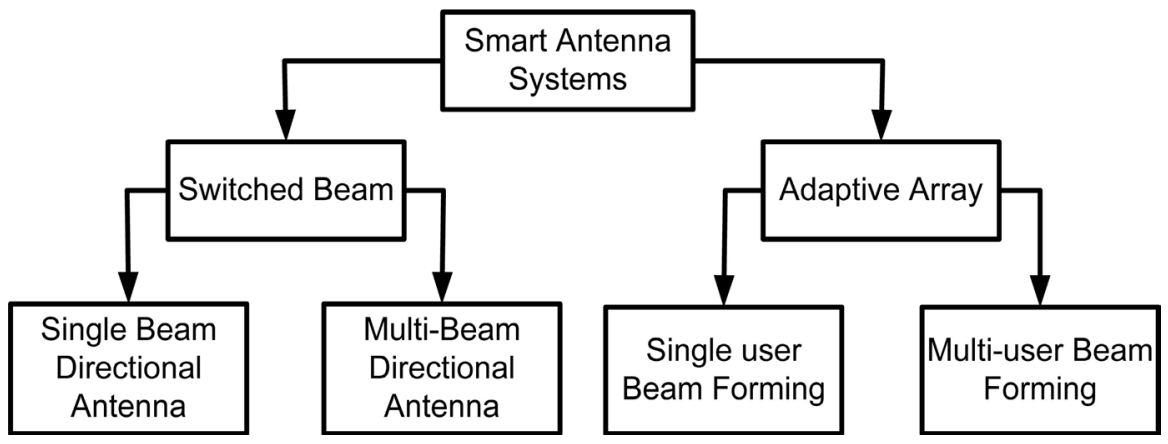

Figure 2. Types of Smart Antenna. 
These systems can be implemented easily and the cost is low. Also, the system uses the algorithms to select the beam. This system needs only interaction among the base station receiver. The main drawback of this system is that the inter-cell interferences among the beams are needed to be handled and also it cannot mitigate the interference components of multipath near to the desired signal [10].

\section{iii) Adaptive BeamForming ( $\mathrm{ABF}$ )}

The adaptive beam forming [11] [12] [13] (ABF) combines the multiple antenna inputs from the antenna array in order to form the narrow beams for individual users present in a cell. The beam former (BF) is also known as adaptive antenna. The beam former indicates the antenna capability (direct the flow of signals in a particular direction). In the Figure 3, $\mathrm{P}$ is the weight vector and it can be formulated by input $\mathrm{I}(\mathrm{t})$ received through various antennas. The adaptive processor will then minimizes the errors $\operatorname{Er}(\mathrm{t})$ among the array output $\mathrm{y}(\mathrm{t})$ and desired signal ds $(\mathrm{t})$.

The ABF needs a proper signal processing, which is more expensive as per the commercial applications point of view. The digital beam forming (DBF) in the wireless communication gives the complex digital data obtained through received signals. The advantage of the beam former is that it adjust the complex weights present at the output end of every array sensor and by which a pattern is produced which optimizes target signals reception at a particular direction with statistical sense. Also, the beam forming estimates the signal coming from the particular direction even at presence of noise and interference of co-channels.

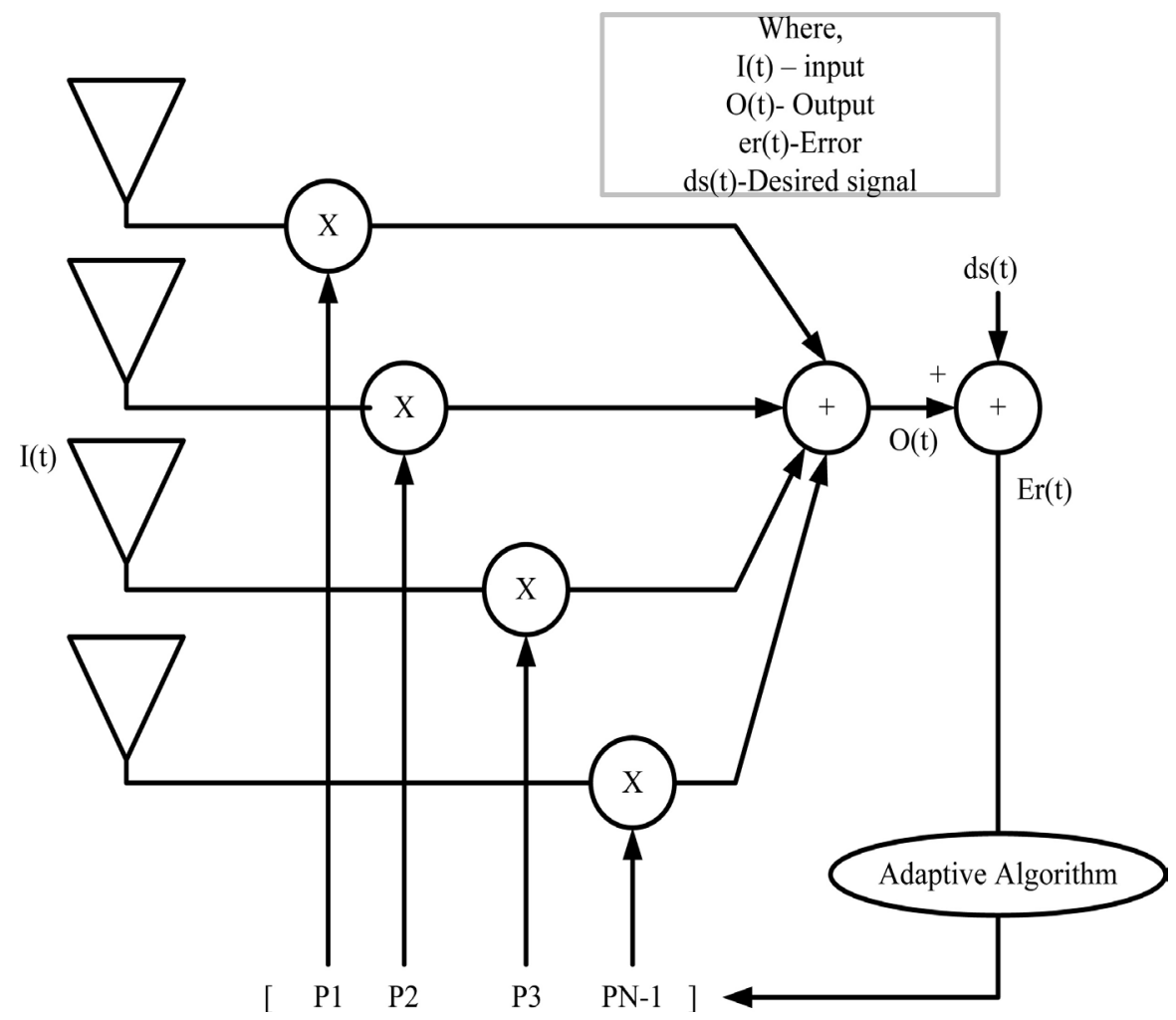

Figure 3. Adaptive Beam forming. 
The ABF can be achieved with the advanced DSP and software's. The energy of an desired beam can generate the significant gain and facilitates the signal extension.

The main disadvantages of the narrow beam are that it faces interferences, allows more users in a same cell at same time and at same frequency. By implementing ABF, cell spectral efficiency can be multiplied up to ten-times. The traditional beam former steers the gain of an antenna in a particular direction of desired signal. There are two variety of algorithm which helps to achieve ABF. i.e. Recursive Least squares (RLS) and Least Mean Squares (LMS) algorithm.

- Recursive Least Squares ( $R L S$ ): This adaptive algorithm, which provides the rapid convergence speed. This algorithm identifies the coefficients which minimizes the weighted linear least squares of the input signals. The input signals in this algorithm are considered deterministic and exhibits its significance in cost of computational complexity [13] [14].

- Least Mean Squares (LMS): This algorithm is presented in 1959 by Window and Hoff as adaptive algorithm. This algorithm uses the gradient based method to calculate the gradient vector of the available data. This algorithm consist an iterative process that brings the successive corrections in negative direction of the gradients with least errors. This algorithm is quite simple and doesn't need a correction functions or matrix inversion [13] [14].

The smart antenna based systems gives the following significances [11]:

i) Enhanced coverage, Enhanced capacity

ii) Enhanced link quality, Enhanced data rate

iii) Low power consumption

iv) High sensitive reception, Reduced costs

v) Suppression of Interference

vi) Lower absorption rate

vii) Enhanced spectral efficiency

viii) Reduced multipath fading

\section{Existing Access Techniques}

In modern communication system, there exist various access techniques and are explained as below and are given in Figure 4 [1] [12] [14] [15].

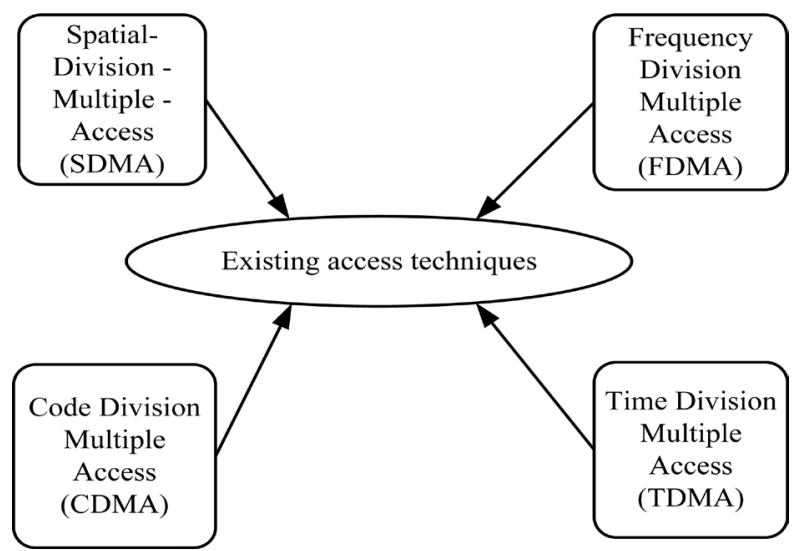

Figure 4. Existing Access Techniques. 


\subsection{Spatial-Division-Multiple-Access (SDMA)}

In this access technique, the access is performed based on the direction of the entering signal. This method helps to enhance the capacity, reduce the interference and improve the entire link quality of wireless communication. This method ranges from the switched beam mechanism to adaptive antenna. The access method enhances the capacity and QoS in the communication network. By using this method several mobiles can be communicated in one base station at same frequency.

\subsection{Frequency Division Multiple Access (FDMA)}

In this access method, "the total bandwidth can be divided with number of simultaneous users, where each user can be allocated with a channel and bandwidth".

$$
\text { i.e. } \text { User allocation }=\frac{\text { Total Bandwidth }}{\text { Users }}
$$

\subsection{Code Division Multiple Access (CDMA)}

The development of these techniques was found in World War II, where the different countries military units started to search the effective technique to block the enemies' radio signals by jamming. The technique spreads the energy of signal information.

\subsection{Time Division Multiple Access (TDMA)}

In this technique, the capacity of channel is can be used as much as possible and later the bit stream can be divided into frames and these frames can be divided as time slots allotted for each users. The system based with this technique uses only two time slots/frame for each user.

\section{Coverage and Connectivity in SAS}

The adaptive antennas can enhance the capacity and or connectivity area of wireless communication system. The coverage area in communication system is just the area where the communication among the mobile unit and the base station takes place [2] [7]. Correspondingly, there exist there exist three essentials respected to SAs such as, Interference mitigation, capacity and range extension and are explained as below.

\subsection{Interference Mitigation/Rejection}

In the populated areas, the enhancement of the capacity is major point. There are two main strategies to enhance the capacity i.e. Interference mitigation (at downlink)/rejection (at uplink). Thus, to mitigate the existing interference, the directional beam can be steered towards the mobiles while to reject the interference by forming nulls/directional beams at base station receives the antenna patterns at interfering direction of co-channel users. 


\subsection{Capacity}

The capacity of an system is the spectral efficiency and also traffic offered by various users. The number of users which supported based on the traffic generated by various users and channels in each cell.

\subsection{Range Extension}

The extension of the coverage in the sparsely populated area is major issue than enhancing the capacity. In these areas, the generated gain of adaptive antennas can extend the cell range to cover the more users and large area than other antennas.

\section{Literature Survey}

This section incorporates with the existing researches in the field of smart antenna. There are various studies have been carried out and have given significant outcomes. In this various recently introduced researches related to Quality of Service (QoS), Routing, Energy Efficiency and security is discussed.

\subsection{Research in QoS of Smart Antenna}

A research of Jain and Agarwal [16] described the coverage and connectivity improvement concept in wireless communication using smart antenna system. It is mentioned that the researches in this field is more as the smart antennas offer better network performance. Author has mentioned that to attain the better network performance the network provider must need to calculate the gain for performance computation using propagation results of smart antenna. Authors have analyzed the performance of the proposed system and found that better coverage in cell area.

The collaborative work of $\mathrm{Li}$ and Wang [17] explains the QoS optimization in OFDM network for moving users by using semi smart antenna s. It is observed that the most of the patterns may change on user movement. In order make better changes in qualified user's movement in pattern a periodic optimization (PO) method is introduced and achieved the same without excess triggering.

The work of Li et al. [18] have given a semi smart antennas implementation to optimize the radio resources in OFDMA network and offer a better quality of service. The semi SAs helps to solve the co-channel interferences in cell edge side and optimize the energy consumption. Author have used the system level simulation and analyzed the proposed system performance by which concluded that the desired throughput has achieved.

The work of Imtiaj et al. [19] described the performance analysis of the various $\mathrm{ABF}$ algorithms in smart antenna. The $\mathrm{ABF}$ algorithm in smart antennas gives null steering, maximum coverage, better system capacity giving enhanced QoS than other antennas.

The performance analysis study on WSN with smart antennas is presented in Skiani et al. [20]. The study mainly concentrated on the WSN issues like routing, QoS, interference, power consumption etc. The study analysis which described 
in the test cases gives that with smart antennas $20 \%$ of QoS, $50 \%$ of efficiency and the power consumption is improved.

In order improve the QoS in vehicular communication by smart antennas optimization method is proposed in Constantinescu and Borcoci [21]. Author is focused on the issues related to the mobility management, scheduling tasks, neighbor discovery and interference range and also the base station issues like availability of bandwidth and coverage, velocity Vs throughput, availability/continuity of service. This study gives the desired research in vehicular communication.

The above research survey is summarized in Table 1.

\subsection{Research in Routing of Smart Antenna}

In this, the recent researches in routing of smart antenna are discussed. These researches are selected from the IEEE Xplore. A Diamond Shaped Mesh Network (DSMN) routing is illustrated in Bao et al. [22] with the cross layer design to attain the benefits of Multi beam SAs. This routing mechanism has two unique features like

a) Cross layer design integrated with routing mechanism with multi beam smart antenna s.

b) The routing is of diamond shape and impalements multipath routes.

The simulation is used for performance analysis and found that high throughput is attained. Author Cikovskis [23] have presented the cancellation of the interpath interference in wireless network by smart antennas. In order to avoid the data degradation by interferences, a smart way of routing and transmission mechanisms are needed to used along with the smart antenna. In this work author have used analytical method to analyze the performance of the smart antenna and found that the cancellation of interferences depends on the degree of antennas freedom used.

A multicast delay based routing algorithm is introduced in the work of Hung et al. [24] by using the smart antenna. In this smart antenna are used because of its reusability and low power consumption. The performance analysis gives that

Table 1. Summary of research in smart antenna for QoS.

\begin{tabular}{|c|c|c|}
\hline Authors & Problem Addressed & Outcome \\
\hline Jain and Agarwal [16] & QoS & $\begin{array}{l}\text { Better coverage and connectivity with } \\
\text { smart antenna }\end{array}$ \\
\hline $\begin{array}{l}\text { Cuthbert and Wang } \\
\qquad[17]\end{array}$ & QoS & $\begin{array}{l}\text { QoS without much triggering using semi } \\
\text { smart antenna }\end{array}$ \\
\hline Li et al. $[18]$ & QoS and radio resources & Optimized resource usage and better QoS \\
\hline Imtiaj et al. [19] & Performance and QoS & Better QoS with smart antenna \\
\hline Skiani et al. [20] & Performance analysis & $\begin{array}{l}\text { Improved QoS, efficiency and power } \\
\text { consumption }\end{array}$ \\
\hline $\begin{array}{l}\text { Constantinescu } \\
\text { and Borcoci }[21]\end{array}$ & Issues and QoS & $\begin{array}{l}\text { Vehicular communication, QoS } \\
\text { enhancement factors }\end{array}$ \\
\hline
\end{tabular}


Table 2. Summary of research in routing of smart antenna.

\begin{tabular}{cll}
\hline \multicolumn{1}{c}{ Authors } & Problem Addressed & \multicolumn{1}{c}{ Outcome } \\
\hline Bao et al. [22] & Smart antenna routing & High throughput and performance \\
Cikovskis [23] & Smart antenna routing & Better cancellation of the interferences \\
Hung et al. [24] & Smart antenna routing & $\begin{array}{l}\text { Better throughput and optimization of power } \\
\text { consumption }\end{array}$ \\
Loh et al. [25] & Smart antenna routing & High throughput and performance \\
Babu et al. [26] & Smart antenna routing & $\begin{array}{l}\text { Enhanced performance compared to } \\
\text { uni-directional antenna }\end{array}$ \\
\hline
\end{tabular}

that the algorithm with smart antenna gives better power consumption and throughput.

In Loh et al. [25] have given the concept of performance assessment of the adaptive routing in WSN by using smart antenna. The smart antenna in this performs the significant role in performance enhancement and power optimization.

Babu et al. [26] given the concept of enhancing wireless network performance by using cognitive radio with smart antenna. Authors have studied the performance of wireless network by using the smart antenna. The architectural design of proposed method with spatial selectivity allows the load sharing in various bands which increases throughput. From the analysis of the simulations, authors work found that the interferences occurred for the licensed users during the implementation of uni-directional antenna. These above literatures are summarized in Table 2.

\subsection{Research in Energy Efficiency of Smart Antenna}

This section describes the research performed to bring the energy efficiency in the smart antennas.

Hanaoui and Mounir [27] exhibited the idea talking about the directional correspondence with smart antenna to improve the power efficiency in wireless communications. Author makes a perspective of ground with hubs by utilizing Matlab. The author concluded with the significance of energy efficiency with smart antennas.

The work of Kristem et al. [28] gives the significant discussion regarding the selection of antenna to achieve energy efficiency in wireless communication. Author presents discussion regarding proper energy allocation, Symbol error probability at pilots and data, and optimal selection rule in time-varying channels for the two schemes.

The significant work of Zhu et al. [29], gives the energy saving mechanism called Transmission Mode (TM) selection in semi SAs. The proposed method is combined with the semi-SAs to attain energy saving. In this, based on the zooming scheme the identified transmission nodes were switched off/ sleeping mode without lowering the cell coverage. The optimization of TM mechanism to attain energy efficiency was defined and used generic algorithm to achieve the optimal solution. From simulation results found that the proposed TM selection 
mechanism in network combined with semi-SAs can offer significant energy efficiency in network.

Later, the research towards the energy efficiency for wireless network with smart antennas in multipath environment is presented in Tang and Ramanathan [30]. Later, Adaptive Antenna (AA) array combined with Multiple-Input-MultipleOutput (MIMO) channel model used for wireless multipath environments. The study gives that energy efficient one hop multicast in such environment.

In Ayodele et al. [31] described the smart antennas analysis to improve the signal quality and also spatial processing. This research work focused on the smart antennas can optimizes the Signal-To-Noise-Ratio (SNR) of multiple antenna arrays in. In order to improve communication channel performance adaptively, a measure such as SNR and dynamic range need to be used. The proposed antenna arrays are adapted and aligned in magnitude and phase. These above literatures are summarized in Table 3.

\subsection{Researches in Security Concerns of Smart Antenna}

This section discusses the selected significant researches towards the security concerns, ABF in smart antenna. The research expressed in Yuanjian and Xiaohui [32] discusses the ABF method in SA system. This work illustrates a new $\mathrm{ABF}$ by analyzing and improving an algorithm based on projection of gradient vector. The proposed algorithm was implemented to a Uniform Linear Array (ULA) and its improved structure to compare its performance with that of the conventional LMS algorithm. The results obtained give the significances of the proposed method in performance and throughput wise. The discussion regarding security system modelling based on smart antenna is found in Oluwole and Srivastava [33]. This work uses three antenna elements array. (i) First element was used to transmit/receive the radio frequency signal. This transceiver used to receive also acts remotely to transmit information signal virtually to base station. (ii) The other two elements in base station were used as descrambler against any illegitimate activities. This work considers the imperative securities challenges such as authentication, attacks, privacy and secrecy. In the choice of frequency bandwidth for the transmission of signal, IEEE standard 802.11 designed for

Table 3. Research in Energy efficiency of smart antenna.

\begin{tabular}{cll}
\hline \multicolumn{1}{c}{ Authors } & Problem addressed & \multicolumn{1}{c}{ Outcome } \\
\hline Hanaoui and Mounir [27] & Energy Efficiency & $\begin{array}{l}\text { Significant energy efficiency with smart } \\
\text { antenna }\end{array}$ \\
Kristem et al. [28] & Energy Efficiency & $\begin{array}{l}\text { Good analysis for selection of antennas in } \\
\text { wireless communication }\end{array}$ \\
Zhu et al. [29] & Energy Efficiency & $\begin{array}{l}\text { Better network energy efficiency with semi- } \\
\text { smart antenna implementation }\end{array}$ \\
Tang and Ramanathan [30] & Energy Efficiency & $\begin{array}{l}\text { Better energy efficiency in MIMO network } \\
\text { Ayodele } \text { et al. [31] }\end{array}$ \\
& Energy Efficiency & $\begin{array}{l}\text { Proficient signal quality and interference } \\
\text { rejection }\end{array}$ \\
\hline
\end{tabular}


Table 4. Research in security of Smart Antenna.

\begin{tabular}{ccc}
\hline Authors & Problem addressed & Outcome \\
\hline Yuanjian and Xiaohui [32] & Adaptive Beam-Forming & Significant energy efficiency with \\
method & smart antenna \\
Oluwole and Srivastava [33] & $\begin{array}{c}\text { Security issues in smart } \\
\text { antenna }\end{array}$ & $\begin{array}{c}\text { Discussed the challenges and } \\
\text { solutions }\end{array}$ \\
\hline
\end{tabular}

wireless system had been maintained. The work concludes an significant scopes of the security issues and solution to overcome. These above literatures are summarized in Table 4.

\section{Existing Research Issues/Research Gap}

From the prior section, it can be seen that there has been various forms and types of contribution from smart antenna in communication system. Majority of the existing research work towards smart antenna has addressed the problems that are closely related to problems associated with highly constraint channel capacity over mobile networks. Hence, we can represent the significant contribution of smart antenna is to assist in enhancing the performance of the system over maximized capacity of channel as well as to improve the spectral efficiency along with explicit enhancement towards coverage. We have also seen that two categories of smart antenna i.e. switched and adaptive antenna has also special contribution towards energy efficiency, QoS, system performance etc. Apart from this, significant issues, there are various significant open research issues pertaining to smart antenna.

\subsection{Open Problems in Adaptive Array Antenna}

Although, we speak highly about adaptive array antenna, however, it is potentially shrouded with pitfalls. The first problem in using adaptive array antenna is its implementation issue which is associated with higher complexity with respect to design. Moreover, such forms of research work have heavy dependencies over precise estimation of channel as well as speed of convergence related to its Beamforming mechanism. Hence, adoption of adaptive array antenna has definitive problems towards implementation in MAC layer. Therefore, applicability of different forms of smart antenna towards cross layer is a significant problem that is still unsolved.

\subsection{Lesser Techniques towards Multicarrier Techniques}

There is comparatively lesser number of studies towards multiplexing techniques over wireless network. For an example, Orthogonal Frequency Division Multiplexing (OFDM) is one of the dominant techniques used in $3 \mathrm{G}$ and $4 \mathrm{G}$ network and a variant of it is also a part of investigation in 5G networks. In reality, there are very number of research journals (only 8 journals published in IEEE Xplore since 2010) towards such forms of multicarrier technologies with respect to smart antenna. It is in a very nascent stage of research. 


\subsection{Ineffective Test-Bench}

It has been observed that majority of the research work carried out in smart antenna has used simulation based study and less number of investigations towards real-time implementation. Although, there is nothing wrong in performing implementation using simulation based study, but existing research work has failed to prove its applicability towards real-time usage. There is not a single benchmarked studied using simulation-based approach posing threat to internal validity.

Apart from this, the existing researches focused on the smart antenna are failed to give the efficient smart antenna system and faces some of the following issues. For the diversity, there is need of multiple antennas at the terminal end. Many of the researchers are thought that adaptively combining the signals of antennas rather than using not blocked antennas. The use of multiple antennas significantly increases throughput in existing system; however it also increases the power and also decreases the quality of communication performance.

\section{Conclusions}

The technology smart antenna is playing a vital role in wireless communication. The smart antenna exhibits various benefits in coverage enhancement, data rate enhancement, spectrum efficiency enhancement, interference reduction, which are all the vital factors in better wireless communication. In this paper, we have discussed the significant factors related to the smart antenna, adaptive Beam Forming algorithm, issues, techniques etc. Also, a section with existing research work is described with different areas of interest in smart antenna. A research gap is included which gives a significant factor to future research interest.

The bandwidth, system performance, signals quality and efficiency are the major concerns in the futuristic wireless communications (OFDM). Thus, the technology like smart antenna and allocation of resources adaptively are used to bring effectiveness in the OFDM systems. But the implementation of ABF can introduce the complexity and by which resource allocation may altered/get affected. Thus, there is a need of proper resource allocation system with smart antenna, which can bring effectiveness in the QoS and reduce the complexity in the allocation.

\section{References}

[1] Tse, D. and Viswanath, P. (2005) Fundamentals of Wireless Communication. Cambridge University Press, Cambridge. https://doi.org/10.1017/CBO9780511807213

[2] Bellofiore, S., et al. (2002) Smart-Antenna Systems for Mobile Communication Networks. Part 1. Overview and Antenna Design. IEEE Antennas and Propagation Magazine, 44, 145-154. https://doi.org/10.1109/MAP.2002.1039395

[3] Winters, J.H. (1998) Smart Antennas for Wireless Systems. IEEE Personal Communications, 5, 23-27. https://doi.org/10.1109/98.656155

[4] Alexiou, A. and Haardt, M. (2004) Smart Antenna Technologies for Future Wireless Systems: Trends and Challenges. IEEE Communications Magazine, 42, 90-97. https://doi.org/10.1109/MCOM.2004.1336725 
[5] Bellofiore, S., et al. (2002) Smart-Antenna System for Mobile Communication Networks. Part 2. Beamforming and Network Throughput. IEEE Antennas and Propagation Magazine, 44, 106-114. https://doi.org/10.1109/MAP.2002.1043158

[6] Choi, S. and Shim, D. (2000) A Novel Adaptive Beamforming Algorithm for a Smart Antenna System in a CDMA Mobile Communication Environment. IEEE Transactions on Vehicular Technology, 49, 1793-1806. https://doi.org/10.1109/25.892584

[7] Bellofiore, S., et al. (2002) Smart Antenna System Analysis, Integration and Performance for Mobile Ad-Hoc Networks (MANETs). IEEE Transactions on Antennas and Propagation, 50, 571-581. https://doi.org/10.1109/TAP.2002.1011222

[8] Choi, S. and Yun, D. (1997) Design of an Adaptive Antenna Array for Tracking the Source of Maximum Power and Its Application to CDMA Mobile Communications. IEEE Transactions on Antennas and Propagation, 45, 1393-1404.

https://doi.org/10.1109/8.623129

[9] Ho, M.-J. and Stuber, G.L. and Austin, M.D. (1998) Performance of Switched-Beam Smart Antennas for Cellular Radio Systems. IEEE Transactions on Vehicular Technology, 47, 10-19. https://doi.org/10.1109/25.661027

[10] Shaukat, S.F., et al. (2009) Sequential Studies of Beamforming Algorithms for Smart Antenna Systems. World Applied Sciences Journal, 6, 754-758.

[11] Chandran, S., Ed. (2013) Adaptive Antenna Arrays: Trends and Applications. Springer Science \& Business Media, Berlin, Heidelberg.

[12] Shan, T.-J. and Kailath, T. (1985) Adaptive Beamforming for Coherent Signals and Interference. IEEE Transactions on Acoustics, Speech, and Signal Processing, 33, 527-536. https://doi.org/10.1109/TASSP.1985.1164583

[13] Kawitkar, R. and Wakde, D.G. (2005) Advances in Smart Antenna System.

[14] Rani, Ch.S., et al. (2009) LMS and RLS Algorithms for Smart Antennas in a W-CDMA Mobile Communication Environment. ARPN Journal of Engineering and Applied Sciences, 4, 77-88.

[15] Jamalipour, A., Wada, T. and Yamazato, T. (2005) A Tutorial on Multiple Access Technologies for Beyond 3G Mobile Networks. IEEE Communications Magazine, 43, 110-117. https://doi.org/10.1109/MCOM.2005.1391509

[16] Jain, M. and Agarwal, R.P. (2016) Capacity \& Coverage Enhancement of Wireless Communication Using Smart Antenna System. 2nd International Conference on Advances in Electrical, Electronics, Information, Communication and Bio-Informatics (AEEICB), Chennai, 27-28 February 2016, 310-313. https://doi.org/10.1109/aeeicb.2016.7538297

[17] Li, A., Cuthbert, L. and Wang, Y. (2015) Dynamic Optimization of QoS for Moving Users in an OFDMA Network with Semi-Smart Antennas. 2015 International Wireless Communications and Mobile Computing Conference (IWCMC), Dubrovnik, 24-28 August 2015, 1068-1072. https://doi.org/10.1109/iwcmc.2015.7289230

[18] Li, A., et al (2014) Optimizing Radio Resources for Heterogeneous QoS-Aware OFDMA Networks Using Semi-Smart Antennas. 2014 IEEE International Conference on Communication Systems (ICCS), Macau, 19-21 November 2014, 112-116. https://doi.org/10.1109/iccs.2014.7024776

[19] Imtiaj, S.K., Misra, I.S. and Biswas, R. (2012) Performance Comparison of Different Adaptive Beamforming Algorithm in Smart Antennas. 2012 th International Conference on Computers and Devices for Communication (CODEC), Kolkata, 17-19 December 2012, 1-4. https://doi.org/10.1109/codec.2012.6509188 
[20] Skiani, E.D., Mitilineos, S.A. and Thomopoulos, S.C.A. (2012) A Study of the Performance of Wireless Sensor Networks Operating with Smart Antennas. IEEE Antennas and Propagation Magazine, 54, 50-67. https://doi.org/10.1109/MAP.2012.6293950

[21] Constantinescu, M. and Borcoci, E. (2012) Optimization Method for Smart Antenna use in WiMAX Vehicular Communications. 2012 th International Conference on Communications (COMM), Bucharest, 21-23 June 2012, 263-266.

https://doi.org/10.1109/ICComm.2012.6262555

[22] Bao, K., et al. (2016) Diamond-Shaped Mesh Network Routing with Cross-Layer Design to Explore the Benefits of Multi-Beam Smart Antennas. 2016 25th International Conference on Computer Communication and Networks (ICCCN), Waikoloa, HI, 1-4 August 2016, 1-5. https://doi.org/10.1109/icccn.2016.7568510

[23] Cikovskis, L. (2014) Inter-path Interference Cancelation in Wireless Ad-Hoc Networks Using Smart Antennas. 2014 IEEE 2nd Workshop on Advances in Information, Electronic and Electrical Engineering (AIEEE), Vilnius, 28-29 November 2014, 1-6. https://doi.org/10.1109/aieee.2014.7020329

[24] Hung, L.L., Huang, Y.W. and Wu, S.H. (2014) Transmissions for Delay-Guaranteed Information Using Smart Antenna Systems. 201410 th International Conference on Intelligent Information Hiding and Multimedia Signal Processing (IIH-MSP), Kitakyushu, 27-29 August 2014, 146-149. https://doi.org/10.1109/iih-msp.2014.43

[25] Loh, T.-H., et al (2014) Assessment of the Adaptive Routing Performance of a Wireless Sensor Network Using Smart Antennas. IET Wireless Sensor Systems, 4, 196-205. https://doi.org/10.1049/iet-wss.2014.0066

[26] Babu, V.R., Ghosh, C. and Agrawal, D.P. (2011) Enhancing Wireless Mesh Network Performance Using Cognitive Radio with Smart Antennas. 2011 International Symposium on Intelligent Signal Processing and Communications Systems (ISPACS), Chiang Mai, 7-9 December 2011, 1-6. https://doi.org/10.1109/ispacs.2011.6146213

[27] Hanaoui, M. and Rifi, M. (2016) Directional Communications with Smart Antenna System to Improve Energy Efficiency in Wireless Sensor Networks. 2016 International Conference on Electrical and Information Technologies (ICEIT), Tangiers, 4-7 May 2016, 203-207. https://doi.org/10.1109/EITech.2016.7519590

[28] Kristem, V., Mehta, N.B. and Molisch, A.F. (2013) Training for Antenna Selection in Time-Varying Channels: Optimal Selection, Energy Allocation, and Energy Efficiency Evaluation. IEEE Transactions on Communications, 61, 2295-2305. https://doi.org/10.1109/TCOMM.2013.032713.120551

[29] Zhu, Y., Zeng, Z., Zhang, T. and Xiao, L. (2012) Transmission Mode Selection for Energy Saving in the CoMP System with Semi-Smart Antenna. 2012 International Symposium on Communications and Information Technologies (ISCIT), Gold Coast, 2-5 October 2012, 855-860.

[30] Tong, L. and Ramanathan, P. (2004) Energy Efficient Multicasting Using Smart Antennas for Wireless Ad Hoc Networks in Multipath Environments. IGlobal Telecommunications Conference, GLOBECOM04, 6, 4109-4113. https://doi.org/10.1109/GLOCOM.2004.1379138

[31] Oluwole, A.S. and Srivastava, V.M. (2016) Analysis of Smart Antenna with Improved Signal Quality and Spatial Processing. Progress in Electromagnetic Research Symposium (PIERS), Shanghai, 8-11 August 2016, 474. https://doi.org/10.1109/piers.2016.7734370

[32] Zhou, Y. and Yang, X. (2016) A Novel Adaptive Beamforming Algorithm for Smart Antenna System. 2016 12th International Conference on Computational Intelli- 
gence and Security (CIS), Wuxi, 16-19 December 2016, 522-525.

[33] Oluwole, A.S. and Srivastava, V.M. (2015) Modeling of RF Security System Using Smart Antennas. 2015 International Conference on Cyberspace (CYBER-Abuja), Abuja, 4-7 November 2015, 118-122.

https://doi.org/10.1109/cyber-abuja.2015.7360505

\section{Scientific Research Publishing}

Submit or recommend next manuscript to SCIRP and we will provide best service for you:

Accepting pre-submission inquiries through Email, Facebook, LinkedIn, Twitter, etc. A wide selection of journals (inclusive of 9 subjects, more than 200 journals)

Providing 24-hour high-quality service

User-friendly online submission system

Fair and swift peer-review system

Efficient typesetting and proofreading procedure

Display of the result of downloads and visits, as well as the number of cited articles Maximum dissemination of your research work

Submit your manuscript at: http://papersubmission.scirp.org/

Or contact ojapr@scirp.org 
Submit or recommend next manuscript to SCIRP and we will provide best service for you:

Accepting pre-submission inquiries through Email, Facebook, LinkedIn, Twitter, etc. A wide selection of journals (inclusive of 9 subjects, more than 200 journals)

Providing 24-hour high-quality service

User-friendly online submission system

Fair and swift peer-review system

Efficient typesetting and proofreading procedure

Display of the result of downloads and visits, as well as the number of cited articles Maximum dissemination of your research work

Submit your manuscript at: http://papersubmission.scirp.org/

Or contact ojapr@scirp.org 